\title{
In-vivo biological effect of Carica papaya leaf extracts on P-407 induced hyperlipidemic Wistar rats
}

\begin{abstract}
To determine the biological effect of Carica papaya leaf extracts on Poloxamer induced hyperlipidemia. Thirty-five healthy albino rats of the same sexes weighing $150-200 \mathrm{~g}$ were divided into seven; group given feed and water only, group induced by an intraperitoneal injection of P-407, groups induced and treated with methanol, ethanol, ethyl acetate, n-butanol and n-hexane leaf extracts. In all the groups, P-407 and the extracts were administered at a dose of $1000 \mathrm{mg} / \mathrm{kg}$ and $30 \mathrm{mg} / \mathrm{kg}$ body weight respectively. At the end of the 14 day, the animals were sacrificed and blood sample were collected for determination of serum levels of: Total cholesterol (TC), Triacylglycerides (TG), Low-density lipoprotein (LDL) and High-density lipoprotein (HDL). The studies showed that animals in induced treated groups significantly $(p<0.05)$ lower serum levels of TC, TG, LDL and significantly $(\mathrm{p}<0.05)$ increased HDL when compared to the P-407 induced hyperlipidemia control. The studies show the phytotherapeutic effect of Carica papaya leaf extracts (methanol, ethanol, ethyl acetate, n-butanol and $\mathrm{n}$-hexane) in P-407 induced hyperlipidemia.
\end{abstract}

Keywords: biological effect, Carica papaya, Poloxamer 407, hyperlipidemia
Volume 6 Issue 4 - 2018

Victor Duniya Sheneni, Isaac Eleojo Shaibu, John Mathias Okpe,Adams Akogwu Omada Department of Biochemistry, Kogi State University, Nigeria

Correspondence: Sheneni Victor Duniya, Department of Biochemistry, Faculty of Natural Sciences, Kogi State University, PMB 1008, Anyigba, Nigeria, Tel +234-8033519009, Email shenenivictor@gmail.com

Received: August 02, 2018| Published: August 31, 2018

\section{Introduction}

Tropical America is the home of Papaya, which was spread to the south by the Indians, and to the caribbean by the Spanish. Caricaceae is the family Carica papaya Linnaeus, (paw paw), belongs to, and it is an herbaceous perennial plant with rapid proliferation rate. ${ }^{1}$ Papaya has a short life span, but has a fruitage period of 20 years. Papaya has a complex type of reproduction as they are hermaphrodite i.e. with both male and female part. ${ }^{2}$ The male trees are rare, but can be obtained when homeowners collect their own seeds. The commercially available papayas are the hermaphrodite trees that produce fruits that are pear shaped. These plants are self- fertilizing. ${ }^{3}$ The plant yields natural substance (Annonaceous acetogenins) in leaf barks and tissues of twig that has potent antitumor and pesticidal activities. ${ }^{4}$ Papayas are rich in self-defense compounds that confer a high level of immunity to attack by insects and to diseases. ${ }^{5}$

Hyperlipidemia is a biomedical condition characterized by a marked increase in any or all of the serum lipid profile and/or lipoproteins. Although high serum concentration of low density lipoprotein (LDL) was thought to be a strong indicator of risk of artherosclerosis, dyslipidemia (abnormal concentration of serum lipids), it can also describe high concentration of total cholesterol (TC) or total glyceride (TG), or low concentrations of high density lipoproteins cholesterol (HDL). Hyperlipidemia is the major predecessor of ailments such as artherosclerosis sudden death syndrome and coronary artery diseases which are lipid related. ${ }^{6}$ The major purpose of treatment of hyperlipidermic patients is to lower the possible risk of future development of ischemic heart disease or the occurrence of further cardiovascular disease or cerebrovascular disease. ${ }^{?}$

Poloxamer- 407 (P-407), a non-ionic surfactant is a block copolymer which consists of polyoxyethylene and polyoxypropylene units. It is popular for its biocompatibility and its ability to deliver drugs for different disease states ${ }^{8}$ and acts as an obstacle in preventing post-surgical adhesions. ${ }^{9}$ P-407 has unusual thermo-reversible properties, which at room temperature is liquid, while at body temperature it aggregates and forms a gel, prior to forming micelles. This property of temperature dependent micelle and gel formation makes them commercially useful in personal care products such as mouth washes, deodorants and skin care products and serves as an inactive substance that serves as the vehicle or medium for a variety of pharmaceutical preparations. ${ }^{10}$

Intramuscular or intraperitoneal injection of poloxamer 407 causes hyperlipidermia in rats depending on the administered dosage as was shown by Johnston et al., 1992, as elevating plasma triacylglycerol (TG) beyond 60 fold, and cholesterol beyond 8 fold backed up by this fact. However, subsequent hyperlipidemic studies have brought about new emerging models prior to Johnsten's findings.

\section{Materials and methods}

\section{Materials}

Collection of plant samples: The present study was conducted between May and July, 2017 in Biochemistry Department, Kogi State University, Anyigba, in Kogi state, Nigeria. Fresh green leaves of pawpaw (Carica papaya) were obtained from the premises of kogi state university, Anyigba, Kogi State. The leaves was cut into smaller portion, sun dried for three weeks at room temperature and reduced to coarse powder using hand blender. The sample was packed into an air tight container before storage until required for further analysis.

Experimental animals: A total of thirty-five (35) healthy albino rats of the same sexes weighing between $150-200 \mathrm{~g}$ were obtained from the Department of Biochemistry Animal house, Faculty of Natural Sciences, Kogi State University, Ayingba. The rats were kept in well aerated cages and allowed to acclimatize for a week before the commencement of the in-vivo study.

Chemicals and reagents: All assay kits were from Randox laboratories Ltd. Ardmore, Co. Antrm UK. Chemicals and reagents 
used were all of analytical grade.

Extraction: Ten (10) gram of the grounded leaves sample was weighed into different conical flasks containing $100 \mathrm{ml}$ of the extractants (methanol, ethanol, ethyl acetate, n-butanol and n-hexane). The contents of the different flasks were shaken and the tops was covered with aluminium foil and kept at room temperature for 48 hours (2days) and filtered off using Whatman filter paper (Cat no 1001 125 ) of pore size $125 \mathrm{~mm}$. The filtrate was concentrated by drying in a water bath maintained at a temperature of $45^{\circ} \mathrm{C}$ until a brownish black residue was obtained. These were kept in sealed containers and refrigerated at $2-4^{\circ} \mathrm{C}$ until required.

Acute toxicity studies: The mean lethal dose $\left(\mathrm{LD}_{50}\right)$ of the extracts (methanol, ethanol, ethyl acetate, n-butanol and n-hexane) was conducted to determine the suitable dose for the evaluation of the effect of the extracts. This was done using the method described by Lorke. ${ }^{11}$

Induction of hyperlipidemia: The inducing agent was poloxamer 407. Before administration, P-407 was completely dissolved in water and refrigerated overnight to aid its complete dissolution. The syringe and needle to be used for the induction was cooled to avoid gelation within the syringe during injection. ${ }^{12}$

Animal Grouping and treatment: A total of 35 rats were used. The rats were randomly divided into 7 groups of 5 rats each:

i. Group I: Normal Control rats fed with normal chow and distilled water only for 14 days (NC).

ii. Group II: Hyperlipidemic Control rats induced without treatment (HC).

iii. Group III: Hyperlipidemic rats treated with methanol extract at $50 \mathrm{mg} / \mathrm{kg}$ body weight/day for 14 days $(\mathrm{H}+\mathrm{Met})$.

iv. Group IV: Hyperlipidemic rats treated with ethanol extract at $50 \mathrm{mg} / \mathrm{kg}$ body weight/day for 14days (H+Eth).

v. Group V: Hyperlipidemic rats treated with ethyl acetate extract at $50 \mathrm{mg} / \mathrm{kg}$ body weight/day for 14 days (H+E.Ace).

vi. Group VI: Hyperlipidemic rats treated with n-butanol extract at $50 \mathrm{mg} / \mathrm{kg}$ body weight/day for 14days $(\mathrm{H}+\mathrm{n}-\mathrm{But})$.

vii. Group VII: Hyperlipidemic rats treated with $n$-hexane extract at $50 \mathrm{mg} / \mathrm{kg}$ body weight/day for 14 days $(\mathrm{H}+\mathrm{n}-\mathrm{Hex})$.
Sample collection: At the end of the $14^{\text {th }}$ day, chloroforminhalation anesthesia was performed on the experimental animals. The anesthetized animals were bled by cardiac puncture. The blood samples were collected and centrifuged at a speed of $2000 \mathrm{r} / \mathrm{m}$ for 10minutes and serum collected into plain sample bottles for lipid analysis.

Serm lipid analysis: Total cholesterol (TC), high-density lipoproteincholesterol (HDL) and Triacylglycerol (TG) were determined by enzymatic method as described by Stein, ${ }^{13}$ low-density lipoprotein cholesterol (LDL) was determined by the method of Friedewald et al. ${ }^{14}$

\section{Statistical analysis}

The results are presented as means \pm Standard deviations. Differences between means were assessed using Analysis of variance (ANOVA) and post test using Dunnett multiple comparison test. $P$ value less than 0.05 was considered significant $(p<0.05)$.

\section{Results}

\section{Changes in total cholesterol and Triacylglycerol}

The result shows that animals in the group induced without treatment shows a significant $(\mathrm{p}<0.05)$ increase in TC and TG when compared with all other groups. The animals induced and treated shows that ethanol extract significantly $(p<0.05)$ decreased the TC and TG when compared to other induced treated groups. The ethanol extract had the highest percentage reduction in TC (48.14) and TG (44.21) when compared with other induced treated groups (Table 1).

\section{Changes in high density lipoprotein (HDL) and low density lipoprotein (LDL)}

The result shows that animals in the group hyperlipidemia group $(\mathrm{HC})$ shows a significant $(\mathrm{p}<0.05)$ decrease in HDL and increase in LDL when compared with all other groups. The animals induced and treated shows that ethanol extract significantly $(p<0.05)$ increase the HDL and decreased the LDL when compared to other induced treated groups. Again, the ethanol extract had the highest percentage increase in HDL (48.71) and reduction in LDL (40.04) when compared with other induced treated groups (Table 2).

Table 1 Effect of different extracts of Carica papaya leaf on total cholesterol and triacylglycerol

\begin{tabular}{lllll}
\hline & \multicolumn{2}{l}{ Total cholesterol (TC) } & \multicolumn{2}{l}{ Triacylglycerol (TG) } \\
\cline { 2 - 5 } Groups & $\begin{array}{l}\text { Concentration } \\
(\mathbf{m g} / \mathbf{d l})\end{array}$ & $\begin{array}{l}\text { Percentage } \\
\text { reduction } \\
(\%)\end{array}$ & $\begin{array}{l}\text { Concentration } \\
(\mathbf{m g} / \mathrm{dl})\end{array}$ & $\begin{array}{l}\text { Percentage } \\
\text { reduction } \\
(\%)\end{array}$ \\
\hline Group one (NC) & $202.35 \pm 0.0 \mathrm{I}^{\mathrm{a}}$ & $59.84^{\mathrm{e}}$ & $126.72 \pm 0.10^{\mathrm{a}}$ & $85.87^{\mathrm{e}}$ \\
Group two (HC) & $503.97 \pm 7.54^{\mathrm{f}}$ & $0.00^{\mathrm{a}}$ & $897.36 \pm 6.30^{\mathrm{f}}$ & $0.00^{\mathrm{a}}$ \\
Group three (H+Met) & $305.30 \pm 22.6 \mathrm{I}^{\mathrm{c}}$ & $39.42^{\mathrm{c}}$ & $572.54 \pm 0.01^{\mathrm{c}}$ & $36.19^{\mathrm{c}}$ \\
Group four (H+Eth) & $261.32 \pm 22.60^{\mathrm{b}}$ & $48.14^{\mathrm{d}}$ & $500.63 \pm 31.49^{\mathrm{b}}$ & $44.21^{\mathrm{d}}$ \\
Group five (H+E.Ace) & $346.63 \pm 22.63^{\mathrm{d}}$ & $31.22^{\mathrm{c}}$ & $677.54 \pm 18.89^{\mathrm{d}}$ & $24.49^{\mathrm{c}}$ \\
Group six (H+n-But) & $421.96 \pm 6.14^{\mathrm{e}}$ & $16.27^{\mathrm{b}}$ & $755.23 \pm 21.22^{\mathrm{e}}$ & $15.83^{\mathrm{b}}$ \\
Group seven (H+n-Hex) & $431.96 \pm 7.54^{\mathrm{e}}$ & $14.28^{\mathrm{b}}$ & $767.12 \pm 22.12^{\mathrm{e}}$ & $14.5 \mathrm{I}^{\mathrm{b}}$ \\
\hline
\end{tabular}

Values are expressed as mean $\pm \mathrm{SD}$ of triplicate determination. Values in the same column with 5 different letter subscripts are significantly different $\mathrm{p}<0.05$. 
Table 2 Effect of different extracts of Carica papaya leaf on high density lipoprotein and low density lipoprotein

\begin{tabular}{lllll}
\hline \multirow{2}{*}{ Groups } & \multicolumn{2}{l}{ High density lipoprotein $(\mathrm{HDL})$} & \multicolumn{2}{l}{ Low density lipoprotein (LDL) } \\
\cline { 2 - 5 } & $\begin{array}{l}\text { Concentration }(\mathbf{m g} / \\
\text { dl) }\end{array}$ & $\begin{array}{l}\text { Percentage increase } \\
(\%)\end{array}$ & $\begin{array}{l}\text { Concentration }(\mathbf{m g} / \\
\text { dl) }\end{array}$ & $\begin{array}{l}\text { Percentage reduction } \\
(\%)\end{array}$ \\
\hline Group one (NC) & $73.35 \pm 0.16^{\mathrm{f}}$ & $62.42^{\mathrm{f}}$ & $50.15 \pm 1.22^{\mathrm{a}}$ & $49.90^{\mathrm{f}}$ \\
Group two (HC) & $45.16 \pm 1.09^{\mathrm{a}}$ & $0.00^{\mathrm{a}}$ & $100.10 \pm 2.12^{\mathrm{f}}$ & $0.00^{\mathrm{a}}$ \\
Group three (H+Met) & $60.65 \pm 1.32^{\mathrm{d}}$ & $34.30^{\mathrm{d}}$ & $68.11 \pm 1.11^{\mathrm{c}}$ & $31.95^{\mathrm{d}}$ \\
Group four (H+Eth) & $67.16 \pm 2.09^{\mathrm{e}}$ & $48.71^{\mathrm{e}}$ & $60.01 \pm 1.10^{\mathrm{b}}$ & $40.04^{\mathrm{e}}$ \\
Group five (H+E.Ace) & $57.16 \pm 1.09^{\mathrm{c}}$ & $26.57^{\mathrm{c}}$ & $82.12 \pm 1.12^{\mathrm{d}}$ & $17.96^{\mathrm{c}}$ \\
Group six (H+n-But) & $50.16 \pm 1.22^{\mathrm{b}}$ & $11.07^{\mathrm{b}}$ & $90.11 \pm 2.22^{\mathrm{e}}$ & $9.98^{\mathrm{b}}$ \\
Group seven (H+n- & $49.11 \pm 2.02^{\mathrm{b}}$ & $8.74^{\mathrm{b}}$ & $92.17 \pm 4.62^{\mathrm{e}}$ & $7.92^{\mathrm{b}}$ \\
Hex) & &
\end{tabular}

Values are expressed as mean $\pm \mathrm{SD}$ of triplicate determination. Values in the same column with different letter subscripts are significantly different $\mathrm{p}<0.05$.

\section{Discussion}

The medicinal effect of plants in the management of diseases is attributed to the presence of the bioactive substances in them. These bioactive substances include flavonoids, saponins, tannins, glycosides, steroids, carbonhydrate, anthraquinone and alkaloids. Bioactive substances in medicinal plants are known for their anti-inflammatory, anti-lipidemic, anti-diabetic, anti-microbial, anti-atherosclerotic and anti-carcinogenic properties. ${ }^{15}$

Poloxamer 407, a non-ionic surfactant is popularly known to cause dose dependent hyperlipidemia ${ }^{16}$ by inhibiting the activity of capillary (heparin releasable) lipoprotein lipase (LPL), the enzyme majorly responsible for the breakdown of plasma lipoprotein triacylglyceride, and indirectly induce the activity of the enzyme 3-hydroxy-3-methylglutaryl COA (HMG COA) reductase, which is the rate determining enzyme for the synthesis of cholesterol, which inherently leads to hypertriglyceridemia and hypercholesterolemia respectively. Abnormal elevation in concentration of lipids such as total cholesterol (TC) and triglyceride (TG) results in a condition known as "Hyperlipidemia".

Hyperlipidemia is responsible for the onset and progression of atherosclerosis, ${ }^{17}$ a major risk factor in the development of coronary heart diseases. ${ }^{18}$ Carica papaya leaf extracts (methanol and ethanol) significantly $(\mathrm{p}<0.05)$ reduced TC and TG concentrations. These reductions in TC and TG suggest the ameliorative potential of Carica papaya leaf extracts (methanol and ethanol) in hyperlipidemia. The elevation of TC concentration in this study was achieved by the indirect stimulation of HMG CoA reductase following an intraperitoneal (i.p) injection of P407 (Johnston 2004). Hence the possible TC lowering effects of Carica papaya leaf extracts (methanol and ethanol) could be attributed to decreased activity of hepatic HMG CoA reductase and/ or stimulation of cholesterol-7-alpha-hydroxylase, which converts cholesterol into bile acids. It could also be due to the presence of saponins, a phytochemical which forms insoluble complexes with cholesterol or their bile salt precursor, thus making them unavailable for absorption. ${ }^{19}$ The results obtained in these studies conform to earlier report by Chukwuka et al., ${ }^{15}$ that bioactive substances in plants possess anti-lipidemic activity.

Increase in TG concentration following P407 i.p. injection results primarily from an inhibition of TG degradation, P-407 directly inhibits capillary lipoprotein lipase (LPL) responsible for plasma
TG hydrolysis. ${ }^{16}$ Carica papaya leaf extracts (methanol and ethanol) reduction in TG levels may have been either due to the activation of endothelium bound lipoprotein lipase which hydrolyses the triglyceride into fatty acid hence decreasing triglyceride levels as seen in a report by Sikarwar \& Patil ${ }^{20}$ or by inhibiting lipolysis so that fatty acids do not get converted to triglyceride.

High density lipoproteins (HDL) scavenges cholesterol, and mops up excess cholesterol and cholesterol ester from the blood and peripheral tissues where they are they are transported from and broken down to bile acids by the liver. HDL plays a crucial role in depleting plasma and peripheral concentrations of cholesterol and prevents atherosclerotic plaque formation in the aorta, ${ }^{20,21}$ and are therefore known as protective cholesterol. The present studies shows significant $(\mathrm{p}<0.05)$ increase in HDL by Carica papaya leaf extracts (methanol and ethanol). This could most likely be because of the increasing activity of the enzyme Lecithin-cholesterol acyl transferase (LCAT), responsible for incorporating free cholesterol into HDL, ${ }^{23}$ which reversibly stimulates the transport of cholesterol and inhibits competitively, the uptake of LDL by endothelial cells and inhibiting the production of oxidized LDL. ${ }^{24}$ Cholesterol transport to the cells of the body is mediated by LDL, which transports $60-70 \%$ of the total cholesterol. Therefore, an elevation in concentration of total cholesterol (TC) consequently leads to increase in LDL.

The increased LDL which was not removed in the process of lipid metabolism is likely to flow into the sub-endothelial space, as well as to undergo oxidation. The oxidized LDL is phagocytised by the scavengers of macrophages and the fat-laden macrophage is left with the lipid core filled with cholesterol after necrocytosis and then arteriosclerosis is initiated. ${ }^{25}$ It was reported that some isoflavones (a type of flavonoid) increase resistance to LDL oxidation, like soybean isoflavones and genistein derivatives. This work also shows significant $(\mathrm{p}<0.05)$ reduction in LDL levels by methanol and ethanol extracts of Carica papaya leaf. This result is in accordance with the work of Baum et al. ${ }^{26}$ who reported that plants secondary metabolites may work by increasing LDL receptors densities in the liver binding to apolipoprotein B thereby making liver cells more efficient to remove LDL from blood.

\section{Conclusion}

In conclusion, the present study have demonstrated that Carica 
papaya leaf has anti-hyperlipidemic effects on P-407 induced hyperlipidemia. Utilizing P-407 model, Carica papaya leaf was shown to be effective in significantly lowering total cholesterol, triglycerides and low density lipoprotein levels; thus it can be used in the treatment and/or prevention of cardiovascular diseases. However, more work is needed to investigate the anti-hyperlipidemic component(s) in Carica papaya leaf and mechanism of action.

\section{Acknowledgements}

None.

\section{Conflicts of interest}

Author declares that there is none of the conflicts.

\section{References}

1. Dick G. Papaya: A tantalising taste of the Tropics. Maricopa County Master Gardener Volunteer information, University of Arizona Cooperative Extension. 2003:1-24.

2. Bruce S, Peter CA. Handbook of environmental physiology of fruit crops.1st ed. 2008. 217 p.

3. Jayasri MA, Mathew L, Radha A. A report on the antioxidant activities of leaves and rhizomes of Costuspictus D. Don. International Journal of Integrative Biology. 2009;5(1):20-26.

4. Mc Langhlin JL, Ratanyake S, Rupprecht JK, et al. Evaluation of various parts of the pawpaw tree, Asiminatriloba (Annonaceae), as commercial source of the pesticidal annonaceous aceto genins. J Econ Entomol. 1992;85(6):2353-2356.

5. Peter RN. Pawpaw (Asimina). In: Moore JN, Ballington JR Editors. Genetic resources of temperate fruit and nut trees. Acta Hort. 1991;20(2):567-600.

6. Grundy SM. Cholesterol and coronary heart disease: a new era. J Am Med Assoc. 1986;256(20):2849-2858.

7. Davey SG, Pekkanen J. Should there be a moratorium on the use of cholesterol lowering drugs? Br Med J. 1992;304(6824):431-440.

8. Johnston TP, Punjabiand MA, Froelich CJ. Sustained delivery of interleukin-2 from a poloxamer-407 gel matrix following intraperitoneal injection in mice. Pharm. Res. 1992;9(3):425-434.

9. Steinleitner A, Lambert H, Kazensky C, et al. Poloxamer-407 as an intraperitoneal barrier material for the prevention of postsurgical adhesion formation and reformation in rodent models for reproductive surgery. Obstet Gynecol. 1991;77(1):48-52.

10. Dumortier G, Grossiord JL, Agnely F, et al. A review of poloxamer 407 pharmaceutical and pharmacological Characteristics. Pharmace Res. 2006;23(12):2709-2728.

11. Lorke D. A new approach to practical acute toxicity testing. Archiv of
Toxicol. 1983;54(4):275-287.

12. Megalli S, Aktan F, Daviesand NM, et al. Phytopreventative antihyperlipidemic effects of Gynostemma pentaphyllum in rats. $J$ Pharm Set. 2005;8(3):507-515.

13. Stein EA. Lipids, lipoproteins and Apolipoproteins. In: Treitz NW Editor. Fundamentals of Clinical Chemistry. 3rd ed. Philadelphia: WB Sauders; 1987. P. 470-479.

14. Friedewald WT. Methods for the determination of LDL Cholesterol. Clin Chem. 1972;18:499-502.

15. Chukwuka KS, Ikheloa JO, Okonko IO, et al. The antimicrobial activities of some medicinal plants on Escherichia colias an agent of diarrhea in livestock. Advan Appl Sci Res. 2011;2(4):37-48.

16. Johnston TP. The P-407-induced murine model of dose-controlled hyperlipidemia and atherosclerosis: A review of findings to date. $J$ Cardiovasc Pharmacol. 2004;43(4):595-606.

17. Poss J, Custodis F, Wernerand C, et al. Cardiovascular disease and dyslipidemia: Beyond LDL. Curr Pharmaceu Design. 2011;17(9):861870 .

18. Vaziri ND, Morris K. Lipid disorders and their relevance to outcomes in chronic kidney disease. Blood Purification. 2011;31(1-3):189-196.

19. Messina MJ. Legumes and soybeans: Overview of their nutritional profiles and health effects. Am J Clin Nutr. 1999;70(3 Suppl):S439S450.

20. Sikarwar MS, Patil MB. Antihyperlipidemic Effect of Ethanolic Extract of Hibiscus rosa sinensis Flowers in Hyperlipidemic Rats. RGUHS J of Pharmaceu Sci. 2011;1(2):117-122.

21. Kim H, Jeong D, Jung H, et al. Hypolipidemic Effects of Sophoraflavescens andits Constituents in Poloxamer 407-Induced Hyperlipidemic and Cholesterol-Fed Rats. Biolo and Pharmace Bulletin. 2008;31(1):73-78.

22. Karmarkar B. Poloxamers and their applications in Pharmacy Student Articles. 2008.

23. Geetha G, Kalavalarasariel GP, Sankar V. Antidiabetic effect of Achyranthesrubrofusca leaf extracts on alloxan induced diabetic rats. Pak J of Pharmace Sci. 2011;24(2):193-199.

24. Yokozawa T, Cho EJ, Sasaki S. The protective role of Chinese prescription kangen-karyu extract on diet- induced hypercholesterolemia in rats. Biological and Pharmaceutical Bulletin. 2006;29(4):760-765.

25. Beckmann N, Cannet C, Babib AL, et al. In vivo visualization of macrophage infiltration and activity in inflammation using magnetic resonance imaging. Nanomed and Nanobiotech. 2009;1(3):272-298.

26. Baum JA, Teng H, Erdman JW. Activities of phytochemicals with LDL receptors. American J of Clin Nutr. 1998;58:545. 